\title{
PERANAN KELOMPOK TANI DALAM PEMANFAATAN LAHAN KRITIS DI NAGARI ARIPAN KECAMATAN X KOTO SINGKARAK KABUPATEN SOLOK
}

\author{
Adian Nawal Hazizah ${ }^{1}$, Yurni Suasti ${ }^{2}$, Widya Prarikeslan ${ }^{2}$ \\ Program Studi Pendidikan Geografi, \\ Fakultas Ilmu Sosial, Universitas Negeri Padang \\ Email: adian.nawal@gmail.com
}

\begin{abstract}
Abstrak
Penelitian ini bertujuan untuk: (1) mendeskripsikan pemanfaatan lahan kritis oleh kelompok tani di Nagari Aripan Kecamatan X Koto Singkarak Kabupaten Solok, (2) menganalisis tingkat produktivitas lahan kritis yang dimanfaatkan oleh kelompok tani di Nagari Aripan Kecamatan X Koto Singkarak Kabupaten Solok. Jenis penelitian adalah penelitian deskriptif. Populasi penelitian ini adalah seluruh anggota kelompok tani yang berjumlah 78 orang yang terdaftar dari 4 kelompok tani yang ada. Pengambilan sampel dalam penelitian ini menggunakan teknik total sampling. Data dikumpulkan dengan wawancara dan observasi. Penelitian ini menemukan bahwa: (1) Luas lahan kritis yang dimanfaatkan oleh kelompok tani di Nagari Aripan adalah seluas 79 hektar. Pemanfaatan lahan kritis di Nagari Aripan menggunakan metode vegetatif dan mekanis. Metode vegetatif dilakukan dengan penanaman rumput gajah untuk menggamburkan dan menyuburkan tanah, metode ini dilakukan diawal pembukaan lahan kritis, selanjutnya metode mekanis adalah dengan pembuatan teras atau sengkedan dan pembuatan drainase. (2) Jenis tanaman yang ditanam dilahan kritis adalah tanaman keras yaitu: cengkeh, durian, rambutan, dan karet. Untuk kelompok tani Tunas Inti menanam tanaman cengkeh, durian, karet. Sementara kelompok tani Bunga Durian menanam tanaman durian dan dua kelompok tani lainnya yaitu kelompok tani Harapan Keluarga dan Kharya Bakti menanam dua jenis tanaman yaitu karet dan rambutan. Tingkat produktivitas cengkeh adalah $83.77 \mathrm{~kg} / \mathrm{ha} / \mathrm{panen}$. Sementara produktivitas untuk tanaman durian adalah bekisar antara 538 - $539.07 \mathrm{~kg} / \mathrm{ha} /$ panen, produktivitas rambutan adalah $875.16 \mathrm{~kg} / \mathrm{ha} /$ panen, dan produktivitas tanaman karet adalah berkisar antara 102$104.82 \mathrm{~kg} / \mathrm{ha} / \mathrm{panen}$.
\end{abstract}

Kata kunci: Peranan Kelompok Tani. Pemanfaatan Lahan Kritis ,Lahan Pertanian

\begin{abstract}
Abstrak
This study aims to describe (1) the role of farmer groups in the business of utilizing critical land into agricultural land. (2) the produktivity of land that has been used as agricultural land by farmer groups in the Aripan village $X$ Koto Singkarak distric solok. The researcht type is descriptive research with quantitative approach. This study uses total sampling means the whole population is sampled from 4 farmer groups. The data were colection by questionnaire then analyzed by quantitative descriptive analysis teachnique with precentage formula and productivity analysis. The results of this study found that: (1) critical land in the village of Aripan area of 79 hecteres, initially in the first year of 2010 this critical land is utilized to be planted elephant grass for the purpose of soil fertility and the following year is grown. Critical land conservation methods includes vegetative and mechanical methods. (2) with annual crops: clove, durian, rambutan, rubber. For farmer groups Tunas Inti plant clove durian and rubber. While the farmer gropus Bunga Durian planting durian and twoother farmer groups that is Harapan Keluarga and Kharya Bhakti plant two types of plans namely rubber and rambutan. The level productivity of clove is $83.77 \mathrm{~kg} / \mathrm{ha} / \mathrm{harvest}$. While produktivity for durian is 538 - $539.07 \mathrm{~kg} / \mathrm{ha} / \mathrm{harvest}$, productivity of rambutan is $875.16 \mathrm{~kg} / \mathrm{ha} / \mathrm{harvest}$, dan productivity of plans rubber is $102-104.82 \mathrm{~kg} / \mathrm{ha} / \mathrm{harvest}$
\end{abstract}

Keywords: role of farmer group, utilization of critical land, agricultural land

${ }^{1}$ Mahasiswa Program Studi Pendidikan Geografi Untuk Wisuda Maret 2018

${ }^{2}$ Dosen Jurusan Geografi sebagai Pembimbing I dan pembimbing II 


\section{Pendahuluan}

Menurut Sri Astuti Soedjoko (2014) lahan kritis adalah merupakan kondisi suatu lahan yang telah mengalami degradasi sehingga lahan tersebut tidak bisa menjalankan fungsinya. Suatu lahan dinilai sebagai lahan kritis bila usaha untuk mengambil manfaat dari produktivitasnya tidak sebanding dengan hasil produksinya. Oleh karena itu perlu upaya untuk merehabilitas lahan tersebut agar produktifitasnya bisa pulih.

Lahan kritis yang bisa dimanfaatkan untuk pertanian adalah lahan kritis memiliki kriteria tertentu. Menurut Baba Barus (2012) lahan kritis mempunyai sifat lereng miring dan berbukit, lapisan tanah tipis, kemampuan menahan air rendah, berbatu-batu, sangat mudah erosi, mengandung garam natrium tinggi yang berdampak tidak baik untuk tanaman. Sarwono Hardjowigeno widiatmaka (2007). Ciri lahan kritis adalah lahan yang sedikit humus keadaan tanah yang kurang subur dan lahan yang sedikit mengandung mineral yang resiko ancamanya besar untuk erosi dan banjir. Untuk itu perlu penanganan yang tepat agar lahan kritis dapat diperbaiki.

Menurut Arsyad (2000) lahan kritis atau tanah yang kritis dapat dijadikan lahan pertanian kembali jika ada pengolahan, pengolahan yang dilakukan mampu menciptakan keadaan tanah yang baik bagi tanaman. lahan kritis yang diolah memiliki kondisi lahan yang berada pada kemiringan lereng 8-25\%, lahan yang kering sulit untuk pengairan,dan kurang subur. Dalam kaitan pengolahan lahan pemerintah Kabupaten Solok memberikan batuan dengan pengelolaan dari kelompok tani. Dalam pengolahan lahan kritis perlu kerjasama dari para petani. Untuk itu dibentuklah kelompok tani Soedarmanto (2003) mengungkapkan bahwa kelompok tani merupakan salah satu upaya pemberdayaan petani untuk meningkatkan produktivitas, dan kesejahteraan mereka. Keberadaan kelompok tani di Indonesia telah lama ada sebagai lembaga komunikasi antar petani dalam menjalankan aktivitasnya.

Kelompok tani merupakan Kelompok tani adalah kumpulan petani yang terkait secara non formal dan dibentuk atas dasar kesamaan, kepentingan, kesamaan kondisi lingkungan (sosial, ekonomi, sumberdaya), keakraban dan keserasian, serta mempunyai pimpinan untuk mencapai tujuan bersama.

Keberadaan kelompok tani sangat membantu mengatasi lahan kritis. Peranan kelompok tani Soekanto (1996:2013) peran meliputi norma-norma yang dihubungkan melalui posisi atau tempat seseorang dalam masyarakat. Peranan adalam arti ini merupakan rangkaianrangkaian peraturan yang membimbing masyarakat dalam kehidupan bermasyarakat sebagai organisasi, suatu kensop perihal apa 
yang dapat dilakukan individu sebagai masyarakat dalam organisasi dan individu yang pening bagi struktur sosial masyarakat, peran kelompok tani diharapkan akan dapat memainkan peran yang lebih baik dimana dalam pelaksanaan tugas dapat dikerjakan dengan baik dan efektif untuk mencapai tujuan kelompok.

Pengolahan lahan kritis secara baik tentu memperhatikan bagaimana pemanfaatan lahan kritis yang bisa memperbaiki lahan tersebut . Untuk memanfaatkan lahan kritis perlu dilakukan dengan baik oleh kelompok tani sesuai dengan langkah-langkah konservasi lahan yaitu menurut Soepardi (1979) : (1) Metode vegetatif yaitu pengolahan tanaman yang ditanam dengan cara sedemikian rupa, sehingga dapat menekan laju erosi dan aliran permukaan. (2) Metode Fisik atau Mekanis yaitu tindakan atau perilaku yang ditunjukan kepada tanah agar dapat memperkecil aliran air permukaan, sehingga dapat mengalir dengan kekuatan tidak merusak. (3)
Metode Kimia yaitu tindakan atau perlakuan kepada tanah agar terjadi peningkatan kemantapan agregat tanah atau struktur tanah, dengan jalan memberikan preparat-preparat kimia tertentu yang dapat memperkecil kepekaan tanah terhadap ancaman kerusakan tanah.

Sekaitan dengan itu beberapa lokasi di Nagari Aripan termasuk lahan kritis dengan luas lahan 231 hektar. Agar menjadi lahan yang produktif pemerintah Kabupaten Solok menggaskan untuk memanfaatkan lahan kritis tersebut melalui program pemanfaatan lahan kritis dengan cara meningkatkan partisipasi masyarakat melalui kegiatan kelompok tani mulai 2010 sampai saat ini di Nagari Aripan, terdapat 4 kelompok tani yaitu Kelompok Tani Tunas Inti, Harapan Keluarga, Bunga Durian, Kharya Bakti yang mengolah lahan kritis. Untuk lebih jelasnya tentang jumlah kelompok tani di Nagari Aripan kecamatan X Koto Singkarak Kabupaten Solok adalah sebagai berikut:

Tabel. 1 Kelompok Tani Di Nagari Aripan Kecamatan X Koto Singkarak

\begin{tabular}{|c|c|c|c|c|}
\hline No & Nama Jorong & Nama Kelompok & $\begin{array}{c}\text { Jumlah } \\
\text { Anggota } \\
\text { (Orang) }\end{array}$ & $\begin{array}{c}\text { Luas } \\
\text { Lahan } \\
\text { (Ha) }\end{array}$ \\
\hline 1 & \multirow{2}{*}{ Jorong Data Tampunik } & Tunas Inti & 23 & 24,5 \\
\cline { 3 - 5 } & & Harapan Keluarga & 22 & 25 \\
\hline 2 & Jorong Data Bungo & Bungo Durian & 17 & 14 \\
\hline 3 & Jorong Pintu Rayo & Kharya Bhakti & 16 & 15.5 \\
\hline Jumlah & & $\mathbf{7 8}$ & $\mathbf{7 9}$ \\
\hline
\end{tabular}

Sumber: Kantor Wali Nagari Aripan Tahun 2016.

Penelitian ini adalah untuk menganalisis bagaimana peranan kelompok tani dalam pemanfaatan lahan kritis di Nagari Aripan dan produktivitas lahan yang telah diolah oleh kelompok tani di Nagari Aripan. 


\section{Metode Penelitian}

Jenis penelitian ini adalah penelitian deskriptif. Penelitian ini di laksanakan pada Desember 2017 yang berlokasi di Nagari Aripan, Kecamatan X Koto Singkarak, Kabupaten Solok.

Populasi dalam penelitian ini adalah:Seluruh anggota kelompok tani di Nagari Aripan yang terdiri dari 4 kelompok tani yaitu Kelompok Tani Tunas Inti, Harapan Keluarga, Bungo Durian dan Karya Bhakti.

Berdasarkan populasi maka sampel yang diambil sebagai responden dalam penelitian ini adalah seluruh anggota sebanyak 78 orang dari tiap-tiap kelompok petani yang ada di Nagari Aripan Kecamatan X koto Singkarak Kabupaten Solok.

Teknik pangambilan sampel yang digunakan dalam penelitian ini adalah Total Sampling. Peneliti menggunakan teknik pengambilan sampel dengan teknik Total Sampling hal ini dengan mempertimbangkan karena jumlah anggota dari tiap-tiap kelompok petani yang ada di Nagari Aripan jumlahnya kurang dari 100 orang. Hal ini berdasarkan apabila subyek penelitian kurang dari 100 orang lebih baik diambil semua (Arikunto, 1997). Untuk lebih jelas dalam pengambilan sampel dalam penelitian ini lihat tabel:

Tabel.2 Klasifikasi Pengambilan Sampel

\begin{tabular}{|c|c|c|c|}
\hline No & Kelompok Sampel & $\begin{array}{c}\text { Jumlah } \\
\text { Anggota }\end{array}$ & $\begin{array}{l}\text { Jumlah } \\
\text { Sampel }\end{array}$ \\
\hline 1 & Tunas Inti & 23 & 23 \\
\hline 2 & Harapan Keluarga & 22 & 22 \\
\hline 3 & Bungo Durian & 16 & 16 \\
\hline 4 & Karya Bhakti & 17 & 17 \\
\hline \multicolumn{2}{|r|}{ Jumlah } & 78 & 78 \\
\hline
\end{tabular}

Su mber: Data Sekunder Wali Nagari Aripan 2016

Untuk mengetahui tingkat lahan kritis sebagai obyek penelitian produktivitas lahan sebagai berikut:

Tabe. 3 Dengan Kategori Produktivitas

\begin{tabular}{|c|c|c|}
\hline No & $\begin{array}{c}\text { Nilai } \\
\text { kriteria }\end{array}$ & Kategori \\
\hline 1 & $0-<50 \%$ & Sangat rendah \\
\hline 2. & $50-<70 \%$ & Rendah \\
\hline 3. & $70-<85 \%$ & Sedang \\
\hline 4. & $85-<100 \%$ & Tinggi \\
\hline
\end{tabular}

Sumber: Dinas Pertanian

Kabupaten Solok 2007.

Pengukuran Tingkat produktivitas lahan kelompok tani di Nagari Aripan dalam kegiatan pemanfaatan ini, ditentukan berdasarkan kategori produktivitas.

\section{HASIL PENELITIAN DAN PEMBAHASAN}

Nagari Aripan Kecamatan X Koto Singkarak Kabupaten Solok adalah salah satu Nagari dari 74 Nagari yang ada di Kabupaten Solok terletak di bagian utara wilayah Kabupaten Solok. Nagari Aripan mempunyai luas wilayah 4.444 ha, dan ketinggian dari permukaan laut adalah 600 mdpl, dengan suhu harian 
$26-31^{\circ}$ C. Berikut peta lokasi Singkarak Kabupaten Solok:

Nagari Aripan Kecamatan X Koto

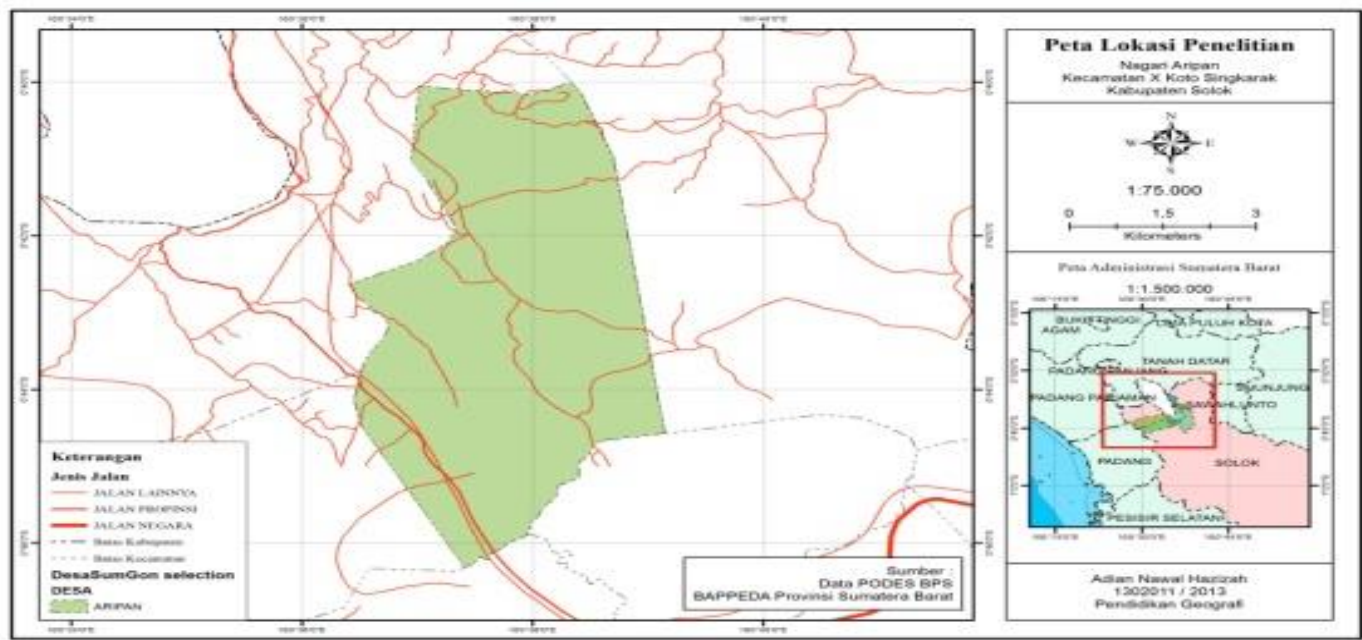

Sumber: Data PODES BPS BA PPEDA Provinsi Sumatera Barat

Daerah ini terdapat lahan kritis seluas 231 hektar. Dalam pemanfaatan lahan kritis di Nagari Aripan petani dari 4 kelompok tani diatas melakukan program kegiatan pengolahan lahan kritis. Adapun bentuk kegiatan pemanfaatan tersebut dijelaskan pada tabel di bawah ini:

Tabel. 4 Bentuk Kegiatan Pemanfaatan lahan Kelompok Tani Nagari Aripan

\begin{tabular}{|c|c|c|}
\hline No & $\begin{array}{c}\text { Bentuk kegiatan } \\
\text { Kelompok }\end{array}$ & Kegiatan \\
\hline 1 & Pemanfaatan/pengolahan & $\begin{array}{l}\text { a. Pembukaanaan jalan dari jalan utama di } \\
\text { Nagari Aripan ke lahan kritis yang akan } \\
\text { dimanfaatkan untuk pertani, panjang jalan } \\
\text { kurang lebih } 5 \mathrm{~km} \text {. } \\
\text { b. pembersihan lahan dengan cara di pangkas } \\
\text { semak } \\
\text { c. Penggamburan tanah } \\
\text { d. Penghijauan kembali dengan menanam } \\
\text { tanaman penutup tanah } \\
\text { e. Pembuatan irigasi seperti bak penampung } \\
\text { air pada setiap lahan }\end{array}$ \\
\hline No & $\begin{array}{c}\text { Bentuk kegiatan } \\
\text { Kelompok }\end{array}$ & Kegiatan \\
\hline
\end{tabular}




\begin{tabular}{|c|c|c|}
\hline 2 & Pemeliharaan & $\begin{array}{l}\text { a. Pemberian pupuk organik ( pupuk } \\
\text { kandang) dan non organik pada tanah } \\
\text { b. Pembuatan guludan pada lahan. } \\
\text { c. Pemakaian mulsa pada tanah } \\
\text { d. Penanaman dalam strip atau penanaman } \\
\text { beberapa jenis tumbuhan dengan jalur } \\
\text { selang seling pada lahan. } \\
\text { e. Pengaturan jarak tanaman }\end{array}$ \\
\hline 3 & Penggunaan. & $\begin{array}{l}\text { Ditanami tanaman perkebunan } \\
\text { cengkeh, durian, rambutan dan karet }\end{array}$ \\
\hline
\end{tabular}

Sumber : Data Primer Kelompok Tani

Kegiatan pemanfaatan lahan

Lahan kritis yang telah kritis pendanaan awalnya dari pemerintah. Dana yang diberikan pemerintah diputarkan untuk kegiatan pemanfaatan lahan, seluruh kelompok tani di Nagari Aripan diberikan dana $\mathrm{Rp} 290.500 .000$ pada setiap kelompok tani.

Tabel.5 Tanaman dan Luas Lahan dimanfaatkan Kelompok Tani Nagari Aripan

\begin{tabular}{|c|c|l|c|}
\hline No & Kelompok Tani & Bibit/Tanaman & $\begin{array}{c}\text { Luas } \\
\text { (ha) }\end{array}$ \\
\hline 1 & Tunas Inti & Cengkeh, durian,Karet, & 24,5 \\
\hline 2 & Harapan Keluarga & Cengkeh, rambutan & 25 \\
\hline 3 & Bungo Durian & Durian & 14 \\
\hline 4 & Karya Bhakti & Karet, durian & 15.5 \\
\hline \multicolumn{2}{|l}{ Jumlah } & & $\mathbf{7 9}$ \\
\hline
\end{tabular}

Sumber : Pengolahan Data Primer

Dari lahan yang digunakan hasil tanaman yang ada pada setiap untuk tanaman tahunan diperoleh lahan kelompok tani yaitu:

Tabel. 6 Hasil lahan kelompok tani Di Nagari Aripan

\begin{tabular}{|c|c|c|c|}
\hline No & Nama Kelompok & Tanaman & Hasil(Kg/1 panen/Tahun) \\
\hline \multirow{2}{*}{1} & Tunas Inti & Cengkeh & 754 \\
\cline { 3 - 4 } & & Durian & 4306 \\
\cline { 3 - 4 } & & Karet & 766 \\
\hline 2 & Harapan Keluarga & Cengkeh & 1383 \\
\cline { 3 - 4 } & & Rambutan & 10502 \\
\hline 3 & Bungo Durian & Durian & 7547 \\
\hline 4 & Karya Bhakti & Karet & 573 \\
\cline { 3 - 4 } & & Durian & 431 \\
\hline
\end{tabular}

Sumber : pengolahan data primer 2017

Pendapatan yang diperoleh dari masing-masing kelompok tani: dari tanaman adalah sebagai berikut (1) Tunas Inti, pendapatan 
kelompok tani dari hasil produksi tanaman di lahan yang kelompok tani manfaatkan adalah $47.82 \%$ jumlah pendapantan 5-6 juta sebanyak 11 orang, dan $4.35 \%$ dengan pendapatan $\geq 9$ juta sebanyak 1 orang. Pendapatan tertigggi dari hasil produksi tanaman di kelompok tani tunas inti adalah $\geq 9$ juta dan pendapatan terendah adalah 3-4 juta. Dari keseluruhan anggota kelompok tani rata-rata anggota kelompok tani pendapatan hasil dari produksi yang telah dibagi kepada kelompok tani adalah 5-6 juta sebanyak 11 orang dengan $47.82 \%$. (2) Kelompok Tani Harapan keluarga. pendapatan kelompok tani dari hasil produksi tanaman di lahan yang dimanfaatkan kelompok tani adalah $54.55 \%$ jumlah pendapantan 5-6 juta sebanyak 12 orang, dan $4.54 \%$ dengan pendapatan 7-8 juta sebanyak 1 orang. Pendapatan tertinggi dari hasil produksi tanaman di kelompok tani Harapan Keluarga adalah $\geq 9$ juta dan pendapatan terendah adalah 3-4 juta. Dari keseluruhan anggota kelompok tani rata-rata anggota kelompok tani pendapatan hasil dari produksi yang telah dibagi kepada kelompok adalah 5-6 juta

sebanyak 12 orang dengan presentase $54.55 \%$. (3) Bunga

Durian, pendapatan kelompok tani dari hasil produksi tanaman di lahan yang dimanfaatkan kelompok tani yang terbanyak adalah $37.5 \%$ jumlah pendapantan $\geq 10$ juta sebanyak 6 orang, dan yang terendah $6.25 \%$ dengan pendapatan 6-7 juta sebanyak 1 orang. Pendapatan tertinggi dari hasil produksi tanaman di kelompok tani Bunga Durian adalah $\geq 10$ juta dan pendapatan terendah adalah 4-5 juta. (4) Kharya Bhakti, pendapatan kelompok tani dari hasil produksi tanaman di lahan yang dimanfaatkan kelompok tani yang terbanyak adalah $41.18 \%$ jumlah pendapantan 1-2 juta sebanyak 7 orang, dan yang terendah $5.88 \%$ dengan pendapatan7-8 juta dan 9-10\% sebanyak 1 orang . Pendapatan tertinggi dari hasil produksi tanaman di kelompok tani Bunga Durian adalah $\geq 11$ juta dan pendapatan terendah adalah 1-2 juta.

Pembagian hasil dalam kelompok tani tunas inti adalah $10 \%$ untuk kelompok dan 90\% untuk anggota kelompok.

Produktivitas tanaman dari kelompok tani Di Nagari Aripan berbeda, karena perbedaan produksi dan luas panen dari setiap kelompok tani. Adapun produktivitas lahan dari ke 4 kelompok tani di Nagari Aripan adalah sebagai beriku:

Tabel 7 Produktivitas Lahan Kelompok Tani Pada Satu Kali Panen/Ha/Tahun

\begin{tabular}{l|l|l} 
No & Nama Kelompok & Produktivitas \\
\hline
\end{tabular}




\begin{tabular}{|c|c|c|c|c|c|}
\hline & & \multicolumn{4}{|c|}{$\mathbf{( K g / H a / 1 p a n e n )}$} \\
\cline { 3 - 6 } & & Cengkeh & Durian & Rambutan & Karet \\
\hline $\mathbf{1}$ & Tunas Inti & 83.77 & 538 & - & 102.13 \\
\hline $\mathbf{2}$ & Harapan Keluarga & 83.07 & - & 875.06 & - \\
\hline $\mathbf{3}$ & Bunga Durian & - & 539.87 & - & - \\
\hline $\mathbf{4}$ & Karya Bhakti & - & 539 & - & 104.82 \\
\hline
\end{tabular}

Sumber: Pengolahan Data Primer Kelompok Tani Di Nagari Aripan 2017

Dari produkivitas lahan pada kelompok tani maka dapat diketahui kategori produktivitas lahan dari ke
4 kelompok tani adalah sebagai berikut:

Tabel.7 Kategori Produktivitas Lahan kelompok Tani di Nagari Aripan Kecamatan X Koto Singkarak Kabupaten Solok

\begin{tabular}{|c|c|c|c|c|}
\hline No & Nama Kelompok & Tanaman & Kategori Produktivitas & $\begin{array}{c}\text { Nilai } \\
\text { Kritria }\end{array}$ \\
\hline 1 & & & & $68.70 \%$ \\
\hline \multirow{2nnyy}{*}{2} & \multirow{2}{*}{ Tunas Inti } & Cengkeh & Rendah & $45.13 \%$ \\
\cline { 3 - 5 } & & Durian & Sangat Rendah & $5.90 \%$ \\
\cline { 3 - 5 } & & Karet & Sangat Rendah & $37.46 \%$ \\
\hline 3 & Bunga Durian & Cengkeh & Sangat Rendah & $35 \%$ \\
\hline 4 & Karya Bhakti & Rambutan & Rendah & $45.22 \%$ \\
\cline { 3 - 5 } & & Karet & Sangat Rendah & $36.90 \%$ \\
\cline { 3 - 5 } & & Durian & Rendah & $50.66 \%$ \\
\hline
\end{tabular}

\section{Sumber: Penelitian Dilakukan Desember 2017}

\section{Pembahasan}

Penelitian ini menemukan bahwa : (1) Peranan Kelompok Tani Dalam Pemanfaatan Lahan Kritis. Luas lahan kritis yang ada di Nagari Aripan 231 hektar dan seluas 79 hektar telah dimanfaatkan oleh Kelompok tani yang ada di Nagari Aripan sebanyak 4 kelompok tani yaitu kelompok tani Tunas Inti, Harapan Keluarga, Bunga Durian, Kharya Bakti. Pemanfaatan lahan kritis di Nagari Aripan pendanaanya dari pemerintah daerah $\mathrm{Rp}$ 290.500.00.

Kegiatan yang dilakukan kelompok tani dalam pemanfatan lahan adalah 1) pemanfaatan dengan beberapa kegiatan yang dilakukan yaitu pembukaan akses jalan pada lahan pertanian, pembersihan lahan dengan cara di pangkas semak Penggamburan tanah menggunakan alat traktor, Penghijauan kembali dengan menanam tanaman penutup tanah, pembuatan irigasi seperti bak penampung air pada setiap lahan. 2) pemeliharaan memiliki beberapa kegiatan yang dilakukan kelompok tani yaitu: pemberian pupuk organik ( pupuk kandang) dan non organik pada tanah, pembuatan guludan pada lahan, pemakaian mulsa pada tanah, penanaman dalam strip atau penanaman beberapa jenis tumbuhan dengan jalur selang seling pada lahan, pengaturan jarak tanaman.3) penggunaan lahan yang 
sudah diolah adalah untuk lahan pertanian dan ditanami dengan tanaman seperti cengkeh, durian, rambutan, karet, dalam kegiatan pemanfaatan lahan kritis kelompok tani menggunakan metode konservasi lahan karena dengan metode konservasi lahan yang kritis dapat diperbaiki.

Tanaman yang ditanam pada lahan kelompok tani di Nagari Aripan berbeda pada setiap kelompok. Kelompok tani Tunas Inti yaitu cengkeh, karet, dan durian. Kelompok tani Harapan Keluarga yaitu cengkeh dan rambutan. Kelompok tani Bunga Durian hanya menanam satu jenis tanaman saja yaitu durian. Kelompok tani Karya Bhakti yaitu karet dan durian.

Hasil produksi dibagi dengan kelompok sebanyak $10 \%$ dan $90 \%$ untuk anggota kelompok pemilik lahan. (2) Produktivitas Lahan Kelompok Tani Di Nagari Aripan Produkivitas lahan kelompok tani di Nagari Aripan masih sangat rendah dikarenakan kegiatan pemanfaatan lahan yang dilakukan kelompok tani baru berjalan 1-6 tahun dan umur tanaman belum terlalu lama, jadi hasil produksinyapun masih sedikit.

\section{Penutup}

Kesimpulan

Peranan kelompok tani dalam pemanfaatan lahan kritis. Lahan kritis yang ada di Nagari Aripan seluas 231 hektar, $34.20 \%$ lahan atau sekitar 79 hektar yang dimanfaatkan oleh 4 kelompok tani yaitu kelompok tani Tunas Inti, Harapan Keluarga, Bunga Durian, Karya Bhakti. Metode yang digunakan oleh kelompok tani dalam pengolahan lahan kritis adalah konservasi lahan meliputi metode vegetatif dan mekanis.lahan yang telah diolah dimanfaatkan untuk tanaman seperti cengkeh, durian, rambutan, karet. Modal awal adalah sebesar Rp 290.500.000. Kelompok tani di Nagari Aripan memperoleh informasi mengenai cara pemanfaatan lahan kritis melalui penyuluhan-penyuluhan yang sering diadakan di Balai Nagari Aripan.

Produkivitas lahan kelompok tani di Nagari Aripan masih sangat rendah dikarenakan kegiatan pemanfaatan lahan yang dilakukan kelompok tani baru berjalan 1-6 tahun dan umur tanaman belum terlalu lama ,jadi hasil produksinyapun masih sedikit.

Saran

Dalam kaitannya dengan kegiatan pemanfaatan lahan kritis di Nagari Aripan, diharapkan dapat dijadikan titik tolak pembinaan pada

perilaku dan tata laku masyarakat Nagari Aripan. Prioritas pembinaan dari pemerintah agar dapat lebih ditekankan pada faktor-faktor pengaruh yang berhubungan secara 
nyata dengan tingkat partisipasi mereka dalam kegiatan pemanfaatan lahan kritis dengan kaidah konservasi tanah di wilayahnya. Untuk meningkatkan peranan kelompok tani dalam mengelolaan lahan. Hasil dari penelitian ini diharapkan mampu memberikan manfaat bagi ilmu pengetahuan sosial dan dapat dijadikan salah satu reverensi terkait penelitian peranan kelompok tani dalam pemanfaan lahan kritis menjadikan lahan pertanian yang merupakan pengembangan ilmu geografi dalam bidang ilmu geografi pertanian.

\section{Daftar Pustaka}

Arikunto, Suharsimi. 1997. Prosedur Penelitian: suatu pendekatan praktik edisi revisi V. Jakarta: PT Rineka Cipta.

Arsyad, S.2000. Konservasi tanah dan Air, Departemen Ilmu Tanah dan sumber daya lahan, IPB.

Sri, Astusi. 2014. Pengolahan sumber daya lahan. www. Sumberdayalahan.com.

Diakses pada 28 Desember 2017

Baba Barus, 2012. Bimbingan Teknis Pengendalian Kerusakan Lahan Kritis, Banten.

Soedarmanto, 2003. Penyuluhan Dan Komunikasi

Pertanian. Fkultas Pertanian Universitas Brawijaya Malang.

Soerjono, soekanto, 1996. Sosiologi

Suatu Pengantar, Jakarta :
PT Raja Grafindo Persada.

Soepardi. G, 1997 Sifat dan Ciri Tanah, Departemen Ilmu Tanah, Fakultas Pertanian. IPB.

Sarwono, Hardjowigeno.2015. Evaluasi Kesesuaian Lahan dan Perencanaan Tataguna Lahan, Gadjah Mada University Press, Yogyakarta 